TECHNO

Vol.21, No.2, Oktober 2020, Hal. 119-124

P-ISSN: 1410-8607, E-ISSN: 2579-9096

\title{
BREAKDOWN VOLTAGE CHARACTERISTIC OF MINERAL OIL IN POWER TRANSFORMER 16 MVA UPDL SEMARANG
}

\author{
Setyo Adi Nugroho ${ }^{1}$, Setyo Aji Priambodo \\ ${ }^{1}$ Department of Electrical Engineering, Diponegoro University, Semarang-Indonesia \\ ${ }^{2}$ Department of Electrical Engineering, Gadjah Mada University, Yogyakarta-Indonesia
}

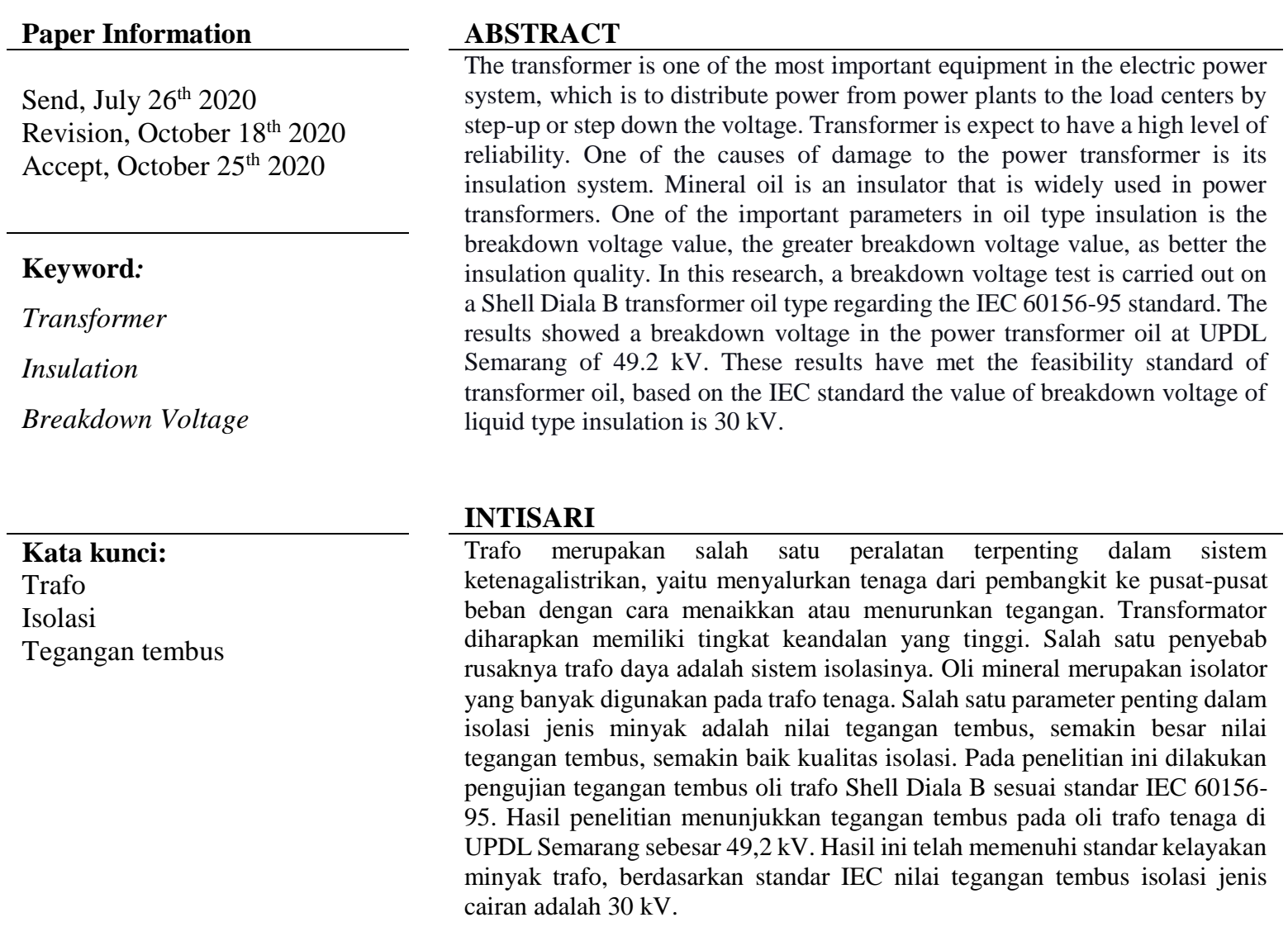

\section{Author Correspondence:}

Setyo Adi Nugroho

Department of Electrical Engineering

Diponegoro University

Jl. Prof. Soedarto, Tembalang 50275

Email: setyo0623@gmail.com

\section{INTRODUCTION}

The electric power system is a bunch of several components such as generation systems, transmission systems, distribution networks, and loads. A power transformer is one of the essential components of an electric power system that functions to step-up or step-down voltage without changing the frequency, thus allowing the most efficient voltage selection. The parts of the power transformers are winding, core, tank, transformer oil, and bushings [1],[2].

Power transformer oil has a function as an insulating medium between the tank and the coil. In operation, the coil of the transformer can arise heat caused by external factors such as ambient temperature or internal 
factors such as loading transformer. So that aside from being an insulating medium, transformer oil also has a function as a transformer cooling medium. Therefore, if the power transformer oil fails to perform its function as an insulating medium or cooling medium, it can cause damage to the power transformer so that the distribution of electric power to consumers is disrupted [3]. Nowadays, there is a lot of research on liquid isolation to knowing the quality of isolation, isolation eligibility, and find the newest isolation materials [4][5][6]. Some studies do the breakdown voltage test to knowing the liquid isolation eligibility that has been used for a while, the breakdown voltage test that doing continuously is not widely doing yet.

We do the breakdown voltage test continuously with some break each time on the mineral oil.. Shell Diala-B is the type of mineral oil that widely used for transformer oil, in its used the quality of the oil can be decreased so that it needs to do some testing to prevent damage to the transformer especially UPDL Semarang transformer. One of the most important parameters of the transformer oil is the breakdown voltage. Some things that affect the breakdown voltage in liquid insulation media are water content, impurities, etc. So to determine the feasibility of transformer oil, it is necessary to test the breakdown voltage value [7]. Based on the IEC 156 standard, the breakdown voltage for liquid insulation is $\geq 30 \mathrm{kV}$ using spherical electrodes and a gap distance of $2.5 \mathrm{~mm}[8]$.

\section{METHODS}

\subsection{Research Flow}

In this research, we will test a breakdown voltage of the liquid insulation transformer oil at UPDL Semarang. The first thing that we do is take a testing sample that is power transformer oil, then the oil is put into the test vessel. The electrodes used to test are adjusted to a distance of $2.5 \mathrm{~mm}$ and set the breakdown voltage testing standard according to IEC-60156-95. This test is carried out 6 times, with the initial time of testing is 5 minutes and the next test delay is 2 minutes. The flow of the liquid insulation breakdown voltage test can be seen in Figure 1 below : 


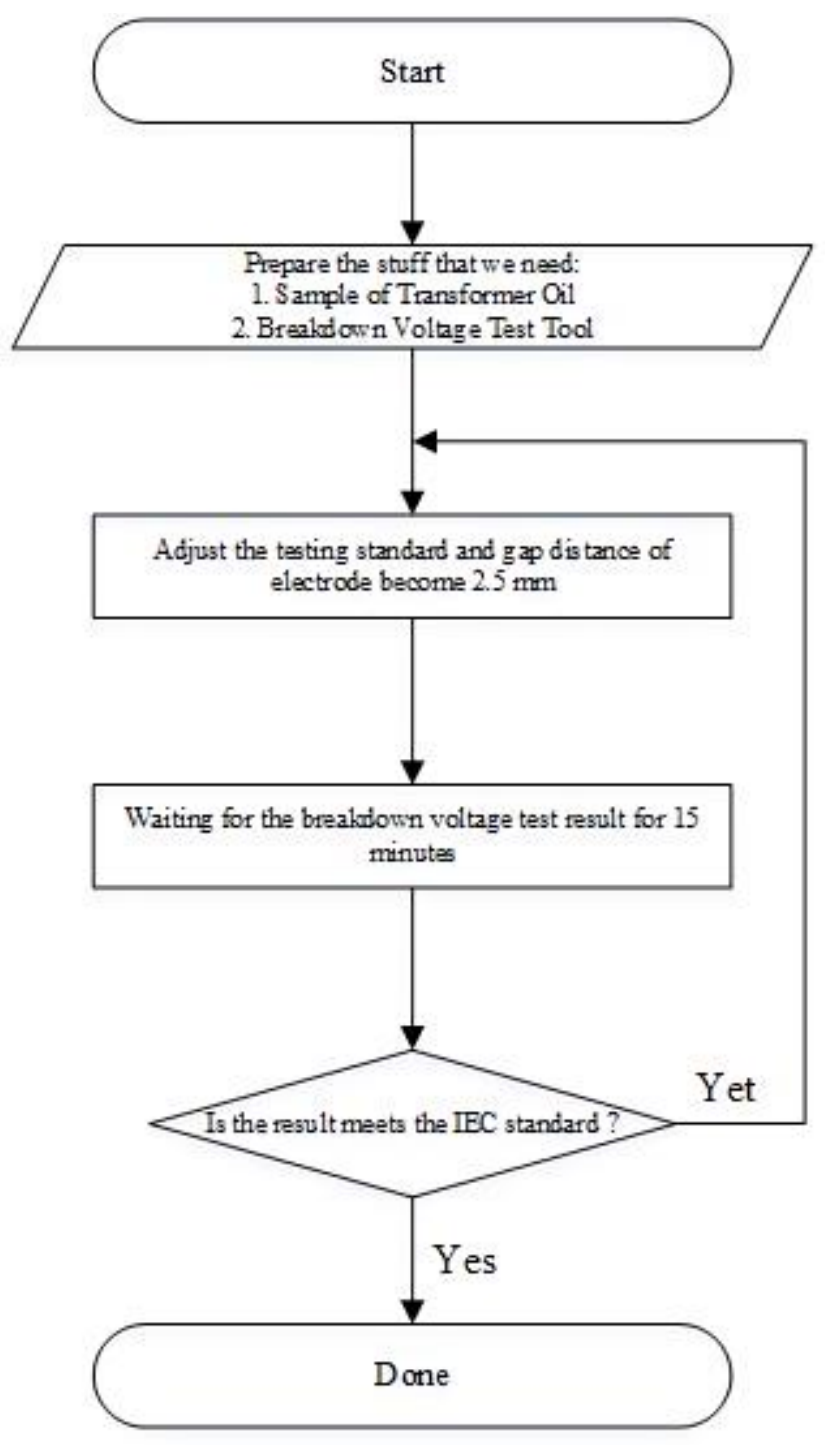

Figure 1. Flowchart

\subsection{Breakdown Voltage Testing Standards}

In Indonesia, the standard makes and publish by PLN or SPLN according to the IEC standard. The electrode used for liquid insulation breakdown voltage test as shown in Fig. 2.

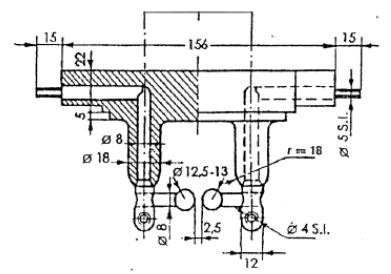

(a)

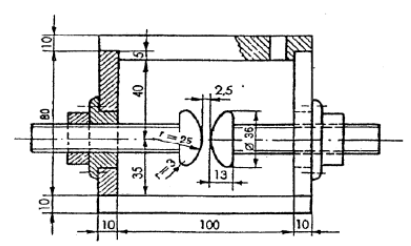

(b)

Source : PLN

Figure 2. Electrode Configuration According to IEC 156 Standard 
The breakdown voltage test performed with VDE electrodes (i.e. spherical electrode) is shown in Fig. 2 (b) with the diameter of the electrode is $3.6 \mathrm{~mm}$. The electrode gap is $2.5 \mathrm{~mm}$. The applied voltage is increased until a breakdown occurs (the increasing rate is $2 \mathrm{kV} / \mathrm{s}$ ).

\subsection{Sample Preparation and Breakdown Voltage Measurement}

Tool and Materials that we used for testing the research :

a. The Oil Power Transformer

The sample used in the experiment is Mineral Oil (MO) Shell-Diala B of Power Transformer UPDL Semarang. Figure 1 shows a sample of Mineral Oil (MO) Shell-Diala B.

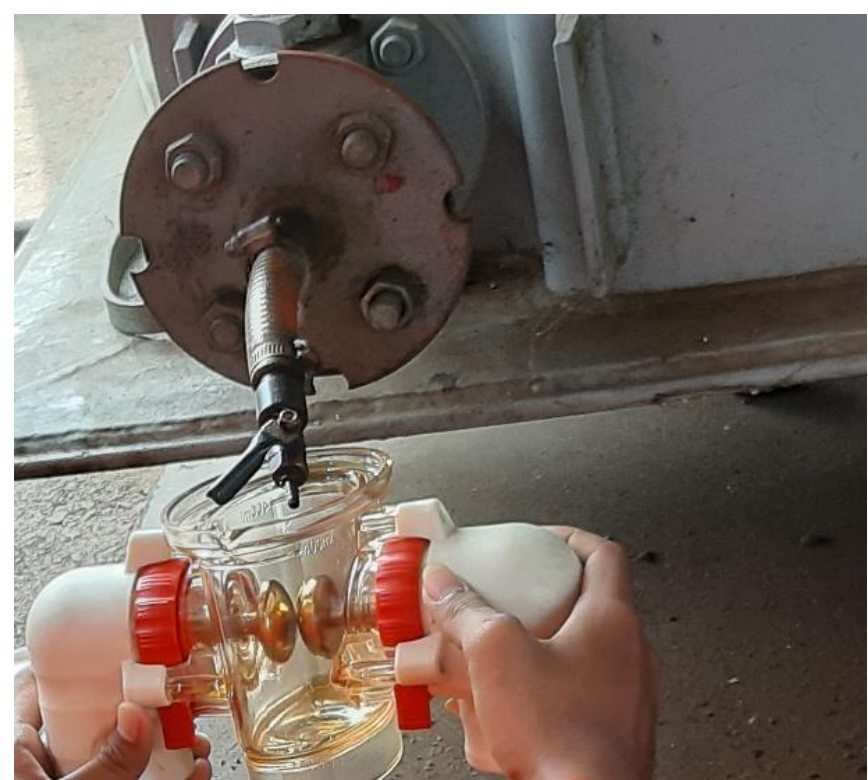

Figure 3. Sample of Mineral Oil Shell-Diala B

\section{b. DPA 75 C Breakdown Oil Measurement}

Figure 2 shows DPA 75 C Breakdown Oil Measurement Test Set is used to evaluate the breakdown voltage up to $100 \mathrm{kV}$. The breakdown voltage test was conducted according to IEC 156 . The test cell has a volume capacity of $400 \mathrm{ml}$ consists of VDE electrodes with a gap of $2.5 \mathrm{~mm}$. It was then automatically started 5 minutes after the start button was pressed. A rate of rising of $2 \mathrm{kV} / \mathrm{s}$ was chosen during the experiment. The breakdown voltage was taken in an average of six measurements with 2 minutes pause between consecutive breakdowns.

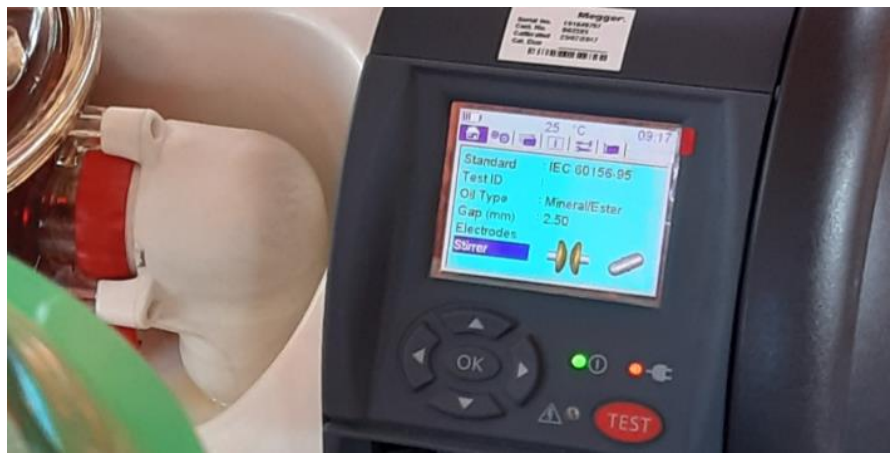

Figure 4. DPA 75 C Breakdown Oil Measurement 


\section{RESULT AND DISCUSSION}

From the data that we get from a breakdown voltage test of transformer isolation oil located in UPDL Semarang, we got 5 different data. These data represent a breakdown voltage value which is different each minute. In minute 5 , the value reaches $61.6 \mathrm{kV}$, that value is the highest amongst four data. It is because the pureness of transformer oil at the beginning of the test is very high, then the pureness of transformer oil decreased time by time while the test is doing.

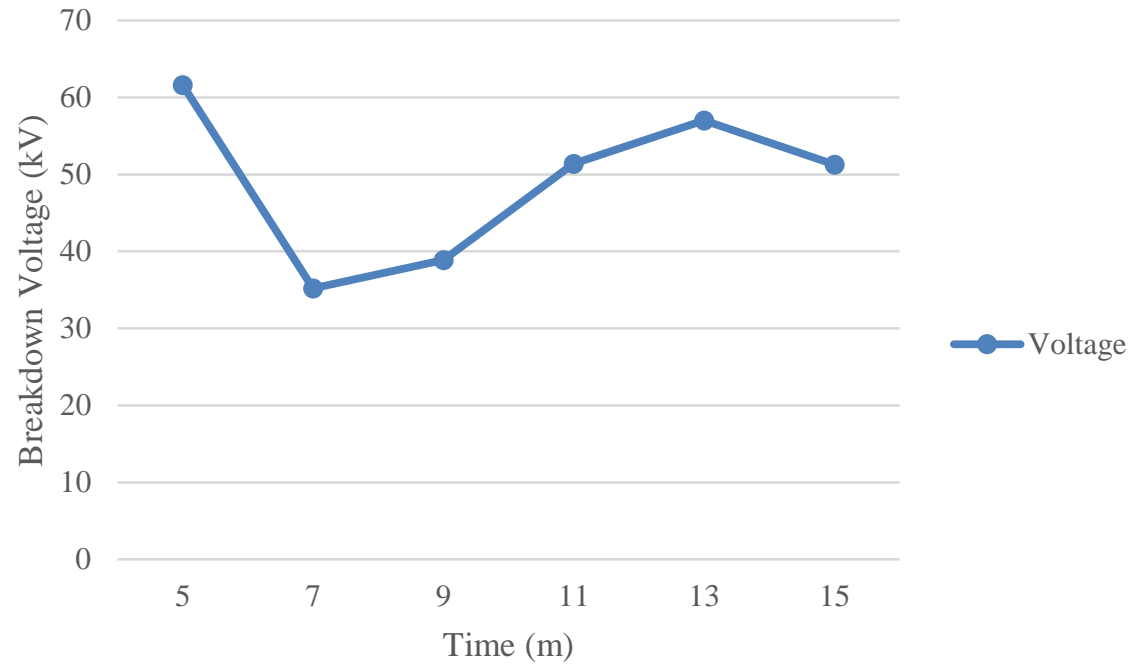

Figure 5. Chart of Breakdown Voltage Test Result for Shell-Diala B Oil

The number of particles contained in the oil will affect the maturity of insulation oil which caused the degradation of the breakdown voltage value. This is because the number of particles contained in the oil will be assemble and connected both of the electrode pole. Moreover, the area of particle field could affect the breakdown voltage value too. If the area of particle field is too big and surpass the hardiness of liquid, it would creating a bubbles around the field which can affect the breakdown voltage value. The more bubbles that contains in the field, the easier isolation oil is discharge. Therefore, the purity of oil insulation will greatly affect the breakdown voltage of an oil insulation.

Based on the result, we can conclude that the average of breakdown voltage in the power transformer oil at UPDL Semarang is $49,2 \mathrm{kV}$. That value is still allowed based on IEC 156 standard. The IEC 156 standard for breakdown voltage of power transformer oil is $\geq 30 \mathrm{kV}$. In the first minute of breakdown voltage test, the value of breakdown voltage is so high. It is because the pureness of transformer oil at the beginning of the test is very high, then the pureness of transformer oil decreased time by time while the test is doing.

\section{REFERENCE}

[1] Putra, Rendy Kamerlisa. Karakteristik Tegangan Tembus Arus Bolak Balik Pada Minyak Jarak Pagar (Jatropha curcas) Sebagai Alternatif Isolasi Cair. JomFTEKNIK Vol. 4. October 2017.

[2] Harief Taufik Kurrahman, Syamsir Abduh, Studi Tegangan Tembus Minyak Kemiri Sunan Sebagai Alternatif Pengganti Minyak Transformator Daya, JETri, Volume 13, Nomor 2, 2016

[3] Mansor, Noor Syazwani. Breakdown Voltage Characteristic Of Biodegradable Oil Under Various Gap Of QuasiUniform Electrode Configuration. IEEE International Conference on Power and Energy (PECon). December 2012.

[4] Jing. Yi and Lehr Jane M. Dielectric Properties of Natural Ester, Synthetic Ester Midel 7131 and Mineral Oil Diala $D$, IEEE Transactions on Dielectrics and Electrical Insulation. Vol. 21. United Kingdom. April 2014.

[5] Olawuni Adeolu, Adejumobi I. A., Breakdown Voltage Characteristics of Castor Oil as Alternative to Transformer Insulation Oil, International Journal of Scientific Engineering and Research (IJSER), Volume 2 Issue 4, 2014

[6] Mosleh M. Alharthi, Sherif S. M. Ghoneim, Ibrahim B. M. Taha., Breakdown Voltage of the Transformer Oils under Certain Conditions, International Journal of Applied Engineering Research, Volume 13, Number 6, 2018.

[7] M.Y, Yusnida. 2012. Breakdown Voltage Characteristic of MO and RBDPO Mixture for Power Transformer Insulation. IEEE Colloquium on Humanities, Science \& Engineering Research. Malaysia.

[8] IEC 156, Determination of the breakdown voltage at power frequency -Test method 
